\title{
Voices from the margins: Towards conservation of local knowledge in psychology during incorporation
}

\author{
T. M. Bakker \\ Department of Psychology \\ University of Pretoria Mamelodi Campus \\ Pretoria, South Africa \\ e-mail: terri.bakker@up.ac.za
}

An earlier version of this article was delivered at the International Society for Theoretical Psychology Xlth Biannual Conference 2005, 20-24 June, Cape Town, South Africa.

\begin{abstract}
The Department of Psychology of what was previously Vista University has recently been incorporated into a number of different institutions as part of the transformation of higher education in South Africa. During the 21 years of its existence, this department had developed particular local expertise in response to the unique opportunities offered by the predominantly black student population they had served and the geographical location of the campuses in townships. However, this kind of expertise is threatened with extinction in the face of the incorporation. Criteria such as local relevance, respect for indigenous knowledge and knowledge application in local township contexts, tend to be silenced in this process. This article describes a response to this situation in the form of a research project aimed at conserving and documenting the local knowledge developed in this department. It explores marginalisation and voice in power/knowledge fields peculiar to the incorporation process and argues for a reconceptualisation of university knowledge towards social responsiveness and an epistemology of uncertainty and inclusiveness.
\end{abstract}

\section{INTRODUCTION}

In June 2002 the Minister of Education announced that the eight campuses of Vista University would be incorporated into different universities as part of the transformation of higher education. By the time this research study was initiated in June 2003, Vista staff had been involved in the first negotiations with the receiving institutions under the incorporation process (Ministry of Education 2003), due to take place from January 2004. This involvement raised questions regarding power/ knowledge relations, identity and voice, within institutional and political context. The study was initiated in an attempt to address some of these questions, specifically as they pertain to the experiences of members of the Department of Psychology. 


\section{BACKGROUND}

\section{Vista University}

Vista University originated in the early eighties under the apartheid government as an attempt to bring university education to urban black people. It thus became the youngest historically black university (HBU) or historically disadvantaged university (HDU) as these institutions were later to become known. It comprised a central campus, the Vista University Distance Education Campus, and seven contact campuses in urban black townships, including Mamelodi (where the author has been situated for 17 years), Soweto, Daveyton, Sebokeng, Welkom, Bloemfontein, and Port Elizabeth. Each of these campuses have now been incorporated into different historically white universities (HWUs), also now known as historically advantaged universities (HAUs), following the Higher Education Act (No. 101 of 1997) as amended (Ministry of Education 2002).

During its 21 years of existence, Vista University underwent many changes, reflecting changes in society and in the political balance in the country as a whole. The management, ethos, vision and mission were transformed during the transition to democracy around 1994, so that it developed a strong African, communitycentred identity (Seepe 2003). This transformation was carried through to the actual curricula when, during the nineties, academic programmes were revised to fit with new legislation to conform to the principles of Outcomes-based Education, the South African Qualifications Authority and the Higher Education Council, in line with the National Plan for Higher Education (Ministry of Education 1997).

The public image of Vista University had always been problematic. During the early years many students perceived it as 'second-rate, apartheid education'. Many entered Vista because they could not afford or qualify academically for HAUs. However, a different set of perceptions had also developed over the years. By 2003, a second generation of students started choosing Vista because they were attracted to its African identity, community engagement, ease of access, and socially relevant academic programmes (Seepe 2003).

\section{Psychology at Vista University}

During the eighties, the Vista department of psychology implemented academic programmes and teaching methods that were largely duplicates of programmes at the HAUs where the staff had been trained or worked before. However, being confronted with a student population who differed largely from the students at HAUs at the time, it soon became clear that these contents and methods had to be modified. Staff were confronted with the needs and background of the predominantly educationally disadvantaged student communities and learnt to modify their teaching so as to become more socially relevant (Bakker et al. 2000). This experience proved invaluable when the whole psychology curriculum was revised during the late nineties. The new curriculum was learner-centred, 
outcomes-based, and aimed to be more suitable to the needs of educationally disadvantaged, English second-language learners (South African Qualifications Authority 2000). The psychology that was taught at Vista by 2003 was measured against standards including local relevance, respect for indigenous knowledge and application in local township and other African contexts. The culture of the department had moved beyond mainstream Euro-American psychology into a serious engagement with the local context (Bakker 2005; May, Bakker, Matla and Molefe 1999).

During this time, the programmes offered in the department were extended beyond undergraduate psychology to include postgraduate professional training programmes: a B.Psych., training registered counsellors in focus areas of community counselling and HIV/AIDS counselling, as well as a Masters in Counselling Psychology. Psychology clinics, where counselling and community services were offered, were developed on some campuses. B.Psych. and Masters students as well as Masters students doing their internships towards registration as psychologists, staffed these clinics. Research projects in the department tended to focus on immediate social issues in surrounding communities and often addressed problems that were previously left out of the loop as a focus of research.

By 2003, the new curriculum was up and running, ready for refinement and revision. It was at this point that the Minister of Education decided to incorporate the separate Vista campuses into different HAUs so that we found ourselves in discussions with receiving institutions discussing the way into the integration.

\section{RESEARCH PROBLEM}

Vista staff members found themselves entering a new discursive context during the incorporation. Their work was now viewed from the perspective of the receiving institution and had to be represented in tables and graphs that measure the work against quantitative and financial standards. The unique context of meaning on the campus had become largely invisible or was re-written in the dominant language of the new order. Most of the academic programmes were discredited, found to be financially too burdensome, 'rationalised' and 'phased out'. The more intangible aspects and value of the work had become invisible. The author's own experience at the time was one of alienation, isolation, marginalisation and voicelessness. The campus was now isolated from the Vista community at large; the local subdepartment was isolated from the rest of the psychology department. As Vista was dismembered, each campus had become like one arm, having to be attached to a brand new body with a different head. We were entering a different institutional culture and finding our work re-presented within its dominant discourses, while the dominant discourses of the past were fragmenting and dissolving. 


\section{PROBLEM EXPLORATION}

In my personal search for a frame of reference to understand this experience, I was led to the following theoretical ideas:

\section{Hegemony and power/knowledge}

After incorporation, we found ourselves entering into a new hegemony, referring to 'that order of signs and practices, relations and distinctions, images and epistemologies - drawn from a historically situated cultural field - that come to be taken-for-granted as the natural and received shape of the world . . . . This is why its power has so often been seen to lie in what it silences, what it prevents people from thinking and saying, what it puts beyond the limits of the rational' (Comaroff and Comaroff 1991, 23). The values and ethos, context and processes of our work had become silenced. They went beyond 'the limits of the rational', in this case the limits of the financial balance sheet of the receiving institution. Things that were previously spoken about at length, such as relevance to local communities, largely fell out of conversations with the new institution.

We had entered a field of power/knowledge (Foucault, 1980) where our knowledges, both in the academic sense and in the sense of personal experience, were ranked very low if at all. This new field of power/knowledge was mediated through certain economically and politically incited 'truths' (Foucault 1980, 131) that differed from the truths we had lived before, such as community engagement. The new truths were politically incited, but selectively so. They were economically incited, but the economic health of the institution was central - the lack of economic opportunities of disadvantaged students had, for example, become marginal.

However, Foucault (1980) suggests that for criticism to do its work, local, popular, indigenous, and regional knowledges that are in circulation but remain at the margins of the dominant knowledge, need to be rediscovered. This accords with a view of university knowledge as having to engage with multiple knowledges circulating in society (Barnett 2000). This study attempted to insurrect some of the local knowledges developed in the Vista Department of Psychology; those that fall at the margins of the receiving institution truths.

\section{The colonial world of incorporations}

My early experiences of interacting with the receiving institution resonated with the metaphors of the colonial world.

- The missionary enterprise

Our induction into the new institution was similar to an induction into a new faith. We found ourselves at the receiving end of a missionary discourse, construing the way of life of 'the native' as inferior and ignorant. We were to be 
improved, inducted into a new way of doing and being, for our own good (Mudimbe 1994). A new identity was conferred upon us, physical space was reorganised and labelled, time reorganised and daily rituals instituted (Mudimbe 1994). Staff members were undergoing induction and staff development programmes, new identity cards were issued, old stationery was discarded, a new flag raised.

- The colonial experience

The incorporation, like colonialism, was clothed in the modernist grand narratives of enlightenment, progress and development (Kvale 1992). We had become like colonial subjects who were examined, documented and surveilled (Foucault 1977). The mission of the coloniser is to make history for people whom they think lack it, to induct those people into an order of activities and values, to impart form to what is perceived as formless (Comaroff and Comaroff 1991). The colonised are drawn into a position where they have to defend their practices in terms of a new order (Comaroff and Comaroff 1991). They are forced to stand outside their own knowledge and describe it to themselves. This research study is part of an effort to stand outside old practices and describe what was previously taken for granted, to ourselves. Like the converted, we had become self-conscious of our own way of life.

- Colonial discourse

We found ourselves at the receiving end of a colonial discourse, where the colonised is made 'other', though deemed to be entirely knowable and visible (Bhabha 1990; Fanon 1967). Comaroff and Comaroff $(1991,15)$ describe this as follows: 'The essence of colonisation inheres less to political overrule than in seizing and transforming others by the very act of conceptualizing, inscribing, and interacting with them in terms not of their own choosing; in making them into pliant objects and silenced subjects of our scripts and scenarios; in assuming the capacity to represent them, the active verb itself conflating politics and poetics'. We found ourselves being spoken about and being represented in forums where we were absent, by speakers who had no experience of our campus. Our own narratives had become marginal.

\section{Marginalisation and voice}

Marginal narratives lack narrative closure and cultural resonance: 'The more familiar people are with the situation described, the higher the cultural resonance will be and the more likely that others will be able to participate with the person whose narrative it is in a way that supports, endorses and elaborates the story the person has to tell' (Weingarten 2001, 115). This research is an attempt at reestablishing cultural resonance for marginal narratives, as well as documenting this knowledge and thereby regenerating it (White 1990). 


\section{Conservation of local knowledge}

The field of heritage conservation speaks of 'intangible heritage' (Bouchenaki 2003) - the network of relationships between artifacts, including language, oral traditions and other cultural patterns. Intangible heritage resources are central to cultural and personal identity. In the same way that biodiversity contributes to a healthy ecology, one can argue that language and cultural diversity contributes to richer knowledge (Abley 2003). This study became an effort at conserving intangible heritage resources in the form of an oral history of a form of local knowledge (Geertz 1993) in the field of psychology.

\section{RESEARCH AIMS}

To create a context in which staff and students of the Vista psychology department can

- voice and document the intangible local value of their work and expertise

- identify aspects of this work that they would like to conserve and take into the future

- explore if and how they have contributed to developing an indigenous and locally relevant psychology

- conserve the intangible value of their work to themselves.

\section{SOCIAL RELEVANCE OF THE STUDY}

It was assumed that the work of the psychology department had made psychology more relevant to those who comprise the majority of the population and who, previously, had remained largely outside the boundaries of mainstream knowledge in psychology. It was assumed that the conservation of such local knowledge may serve as a resource that may be of benefit to future developments in the discipline within the context of the new institutions. Finally, it was hoped that the process of engagement with the research would assist participants with the incorporation process as it would conserve a discursive context of legitimisation for participants.

\section{RESEARCH PARADIGM}

The study departs from a post-modern (Kvale 1992), social-constructionist (Gergen 1999) paradigm. It assumes a self-reflexive stance, recognising that 'what I describe in my research is in no way existent apart from my involvement in it - it is not "out there" ' (Steier 1991, 1). The research is a world that is constructed by inquirers who are, simultaneously, participants in their worlds. It becomes a story that a group tells itself about itself (Geertz 1993; Steier 1991). This research attempted to document the story the psychology group at Vista told itself about itself. Such research is a social process, rooted in language, not in the sense of a 
symbol system for mapping the world as it is, but as a performative means for coordinating activities (Gergen and Gergen 1991). Research then becomes conversation and dialogue.

\section{Research and university knowledge}

The study further assumes that "knowledge-making cannot be neutral and disinterested but is a political process in the service of particular purposes, and one which has been institutionalised in favour of the privileged' (Hall, Gillette and Tandon 1982, as cited in Reason and Bradbury 2001, 6). Knowledge-making in psychology has, similarly, been institutionalised in favour of the privileged in South Africa. Vista University offered a unique opportunity to connect large segments of South African society directly to university teaching and resources. These segments tend to, universally, stay disconnected from universities. Greenwood and Levin $(2000,90)$ describe this situation as it pertains to research; the same could be said of teaching and community service: 'Many groups do not have significant impacts on the focus of university research. Community members, small-scale organisations, minorities, and other powerless or poor people who want assistance with broad social change issues are looking for solutions to everyday problems in particular contexts ... These social groups, belonging to the middle and low end of society's power spectrum, are poorly connected to universities and rarely influence university research agendas . . socially relevant research is marginalised within universities'.

Brulin (2001), Greenwood and Levin (2000) and Kraak (2000) argue that universities need to be accountable, open and responsive to the communities in which they are situated. Calls have also been made by government, through bodies such as the Council on Higher Education (CHE), for universities to get more involved in the community (CHE 2004). Similarly, Humphreys and Conlon (2003) argue for situating tertiary education institutions within disadvantaged and relatively excluded societies and geographical areas, so as to impact directly upon and rectify current inequalities. They argue that those higher education institutions located in previously disadvantaged communities must be nurtured and encouraged to develop their institutional strengths. They warn that if, by creating a smaller number of larger institutions, South Africa "breaks the links between previously disadvantaged higher education institutions and their localities, then the capacities of these . . . universities to help rectify rather than perpetuate the inequalities of Apartheid, could be weakened' $(2003,72)$. The Vista campuses were situated in exactly such localities. Such localities also offer an opportunity for university knowledge to be informed by societal knowledge (Barnett 2000) and for a shift away from elite and insular institutions toward more open and responsive systems of teaching and learning (Kraak 2000).

As the incorporation process prioritises the knowledge of the privileged receiving institutions, this study is not neutral or disinterested. It rejects the notion 
that knowledge generation can or should be apolitical and value free (BrydonMiller 1997) by making explicit the link between the Vista campuses and communities that have traditionally been marginalised within both universities and the dominant social science knowledge (Humphreys and Conlon 2003). It demands this legitimisation also to affirm the validity of personal and communal experience in the face of the impersonal and dividing practices of the incorporation.

Such a position is in line with an 'epistemology of uncertainty' (Barnett 2000, $420)$ and a 'therapeutic epistemology' $(2000,418)$ as a response to the current supercomplex proliferation of knowledges, so as to develop university knowledge that is appropriate to this age. According to this position, knowledge evolves through an active engagement with human experience and repressed claims to knowledge. It offers room for negotiation with different frames of meaning, rather than the pursuit of objective knowledge and truth.

\section{RESEARCH METHOD}

The research method was inspired by the work of qualitative researchers (Denzin and Lincoln 2000) specifically in the field of action research as participative inquiry and practice (Brydon-Miller 1997; Reason and Bradbury 2001). It was concerned with 'the oral, the particular, the local and timely' (Toulmin 1990, 186). The study focused on how participants currently, locally and at the time of the incorporation, perceived the value of their work.

\section{Research participants}

Participants consisted of staff members of the then Vista department of psychology (across campuses), as well as senior students and previous students. Participation was voluntary.

- Sampling

A snowball sampling procedure (Neuman 2000) was followed. The number of participants were to be increased until a saturation point in themes in the data was reached and/or time had run out to complete the project. Saturation in themes was reached at about the time that time ran out towards October 2004.

Participants at Mamelodi campus were invited to enter the process through personal conversations. Staff members at more distant campuses received letters explaining the project, their role as participants as well as issues of anonymity.

- Description of participants

A total number of 25 participants were involved. 13 participants were full-time lecturing staff in the department. The number of years that they had been lecturing at Vista ranged between three and 21 years. Lecturers were situated at 
five of the Vista campuses. Lecturers, senior lecturers, associate professors and full professors were involved. Most of the staff who took part in the study had been actively involved in the department in various management roles.

14 Participants were, or had previously been, students at undergraduate, Honours, B.Psych. or Masters level. Four were, or had previously been, intern psychologists at one of the Vista psychology clinics. Categories overlap as some participants had been involved at more than one level, in more than one role, and/or on more than one campus.

Ten participants were male and 15 were female. Eight were black and 17 were white.

\section{Data collection}

The research questions were explored with participants through 14 unstructured individual and three focus group interviews. All staff and some students were interviewed individually. One participant contributed only in written form. Approximately 18 hours of interviews were audio-recorded and transcribed by the researcher.

The interviews were loosely organised around the following questions:

- What do you consider valuable in the work you did on your campus and that we did together as a department?

- What did you personally find valuable in the way we went about it?

- What was unique about it all?

- What is worth conserving?

- Would you say that our work together contributed to the development of an indigenous psychology? How do you understand this concept?

Most of the data was collected during the first half of 2004, immediately after the incorporations took place.

\section{Data analysis and documentation: Testimonio}

The researcher identified themes in the material and then ordered and summarised the information in the form of a collective statement loosely based on the concept of testimonio ${ }^{1}$ (Beverley 2004; Randall 1985). This statement was then offered to participants for reflection, addition and correction. After further changes, the final collective statement was made available to all participants. Aspects of the documentation that have particular bearing on the development of an indigenous psychology (Heelas and Lock 1981; Kim and Berry 1993; Odora Hoppers 2002) on specifically the Mamelodi campus was reported on in a separate article. ${ }^{2}$

Testimonio is a heterogeneous form. Beverley (2000) defines it provisionally as follows: 'A testimonio is a novel or novella-length narrative, produced in the form of a printed text, told in the first person by a narrator who is also the real 
protagonist or witness of the events she or he recounts ... . The production of a testimonio generally involves the tape-recording and then the transcription and editing of an oral account by an interlocutor' (2000, 555-556). This study employs a polyphonic testimonio, where the document is constituted of accounts by different participants in the same event. The purpose of a testimonio is to give voice to those who would be silenced by a larger, more dominant discourse.

The predominant formal aspect of the testimonio is 'the voice that speaks to the reader through the text of an I that demands to be recognized' (Beverley 2000, 556). The reader is meant to experience the voice as a mark of a desire not to be silenced or defeated. 'If the subaltern could speak - that is, speak in a way that really matters to us, that we would feel compelled to listen to, then it would not be subaltern ... One of the things being subaltern means is not mattering, not being worth listening to, or not being understood when one is "heard" . . . The human sciences and the university are among the institutional constellations of power/ knowledge that create and sustain subalternity' (Beverley 2000, 559-562). What testimonio asks of its reader is a possible solidarity (Rorty 1985) through the text. In this study, its purpose is to create solidarity amongst the participants as well as between the participants and any potential reader.

\section{Quality control}

The study employed quality control measures derived from the qualitative research tradition, including verification and authenticity (Creswell, 1998). Transcripts of interviews, as well as the draft testimonio, were submitted to participants for correction and comments. Interviews with students and previous students served as counterbalance to and verification of the perceptions and experiences of the staff.

\section{Ethical issues}

Permission to run the project was obtained from the Head of Department of Psychology and the Dean of the Faculty of Arts at Vista University during 2003. Participants partook in the study on a voluntary basis after having received full information on the project. All responses were confidential and extracts thereof appear anonymously in the final collective statement and with participants' consent. Recordings and transcripts were destroyed after completion of the study. Personal and identifying details of participants, campuses and universities (with the exception of Vista University) are not mentioned in the testimonio.

\section{RESEARCH THEMES}

The novella style-length of the testimonio ${ }^{3}$ precludes it being represented here. It is written in the first person plural and the text consists mostly of verbatim excerpts from the interviews. The following are some of the themes included: 
- Encounters of a disconcerting kind

We all struggled with the interface between the psychology and teaching philosophies that we were taught at other universities, and teaching psychology at Vista. We initially felt that we had failed in our teaching. We had to innovate and find new ways of engaging students.

- Stretching boundaries

We found that the boundaries around our roles and functions were very often challenged. This enriched our work not only as teachers but also as managers, supervisors and therapists. As lecturers, we were involved with and available to our students. The boundaries of therapeutic relationships had to be extended due to a lack of referral systems and resources in the community. The boundaries of the discipline were challenged and extended.

- The interface between knowing and not knowing

In the context where we worked, we were continually forced to examine your own assumptions, and to be aware that they may not be valid for everybody else, whether a colleague on a different campus, a student, or a client.

- Diversifying diversity

We all had to confront diversity in many different and often ambivalent forms. We struggled with issues of race, culture, socio-economic class, sexual orientation and gender. We became more accepting of diversity and extended our curriculum and teaching methods to reflect this.

- Listening and learning about looking

We had to learn to look and listen in new ways, to students, clients, the community and our colleagues in the university. This required a willingness to learn from the context.

- Transforming our curriculum, transforming ourselves

The curriculum transformation process impacted greatly on our work and ourselves. There was a parallel process of transformation running through the country, the university and the department. Our interaction with our students expanded our awareness, so that there was significant change in the curriculum in terms of making it more accessible to the students.

- From the curriculum to the community and back

The process of curriculum transformation involved an intense community involvement. Developing a new curriculum meant reacting to the community, developing new learning material, and feeding it back into the community. There was a cyclical feedback process which informed the curriculum, as well as the research we were doing. We integrated teaching, community service and research.

- From research to re-search

Our involvement in the communities surrounding us informed our research as well as the research done by our postgraduate students. Research tended to be more qualitative, exploratory, locally relevant and personally engaging. 
- Local relevance and indigenous psychology

We have worked hard to build a psychology that is locally relevant. Many of us have also become attracted to developing and exploring the idea of 'indigenous psychology'. We stay committed to try to bring psychology home. There was a sense of developing something new and of extending the boundaries of the discipline. We became aware of the cultural limitations of psychology texts and we found that students would participate more actively in their learning when the learning material and examples were closer to their own life experiences. We found that students made significant contributions to our knowledge.

- Of dusty streets and chickens - resources and opportunities

Working in the townships provides a unique environment for engagement with communities at the lower socio-economic end of the spectrum. It also provides opportunities to become aware of non-material resources in the context. Part of our transformation was that we had learnt to respect this context and learn from it.

- Access to education for the disadvantaged

We are proud of having been part of a process where those who were economically, socially and educationally disadvantaged, could gain access to university education, despite the controversy surrounding the image of Vista. Our personal experiences speak of an awareness of some of the challenges faced by the disadvantaged in society and at university.

- Our work is our calling (in hardship)

We feel personally involved with and dedicated to our work. Vista was never an easy context to work in. We had to face many hardships through the years. Some of us have experienced trauma and painful experiences at work, that have impacted greatly on our lives. However, we have a passion for what we do. Our personal, professional and academic identities are tied up with our work. We stayed committed to our students through unrest, class boycotts, sometimes violence.

- A sense of personal agency

The climate in the department has been one where people were given autonomy and room to develop a sense of personal agency in their work. We value our sense of personal agency, which stands alongside a culture of inclusivity, rather than exclusivity, as well as a sense of freedom, rather than conformity.

- Speaking for ourselves - democratic, participative values

We have learnt to speak for ourselves. We feel we have a right to participate in decision-making, and that democratic values are sacred. We are used to having a say in most decisions that impact on our work and find that this improves our work.

- From hierarchy to community

The management structure and organisational culture in the department changed from a traditional hierarchical top-down management system, to a more egalitarian, participative system. This went along with decentralisation, so that subdepartments and individuals gained more autonomy. However, the autonomy went along with a strong sense of belonging. This egalitarian way of 
relating extended to the campuses as well, where relations were formed around a sense of community and not always only around organisational roles in a rigid hierarchy.

- Just get out there and do it - A mindset

We find that we have acquired an attitude towards our work that involves a readiness to engage and a willingness to be flexible in the face of obstacles. There is a pro-active attitude of 'can-do', often in the face of a lack of resources, that filters down to the students as well.

- Abundance and riches amidst a lack of material resources

Many of us have experienced richness and abundance in our work despite the fact that we have had to work amidst a lack of material and financial resources. Instead of drawing on material resources, we draw on personal resources. What is important to us is who we are and on our relationship with others, not what we have.

- Embeddedness and belonging; being at home

We experience a sense of belonging where we work, and in the surrounding context. The university was very much a part of the local community. We feel it is important to develop a situatedness and embeddedness over time in the context, to work effectively.

- Chaos and innovation; absurdity and laughter

The larger Vista system was often characterised by chaos, but we feel there is a link between this and the creativity we could enter into. It was possible to develop a departmental system that had enough 'disorder', in a positive sense, to be able to be creative, to constructively innovate. Some of the chaos in the larger system was destructive, but we emerged with an appreciation for absurdity, flexibility, laughter, and a sense of constructive marginality, in the sense of a willingness to move beyond the familiar.

\section{REFLECTIONS ON THE RESEARCH PROCESS}

Participants were enthusiastic about reflecting on their work and expressed relief at having this opportunity. However, at the time of the interviews, the incorporation process was already well under way and most staff chose to also talk about their experiences of the incorporation itself, although this was not part of the original purpose of the study. All staff spoke about experiences of marginalisation, alienation, and voicelessness, with the exception of only one participant, who felt largely welcomed in the receiving institution. Some had found the experience so unpleasant that they had decided to leave the university. Most staff expressed concern that the incorporation would deny access to students who, previously, would have entered university education through Vista.

The students were attracted to participate because they felt Vista had offered them something of value that they believed they would not have had elsewhere. A number of students interviewed would not have entered university education or 
professional training programmes at all, due to financial or entry requirements, had it not been for Vista. The new curriculum and postgraduate professional training programmes attracted students who were keen to extend the boundaries of psychology to fit with present-day realities in their lives. Some black students who had felt alienated from their communities when studying at other universities felt 'at home' at Vista. Postgraduate students from other communities felt attracted to psychology at Vista so as to extend their skills and knowledge. Students expressed appreciation for the outcomes-based learning approach, the African focus of the curriculum, the situation of the campuses in townships, and the personal involvement of staff in their learning. They also expressed concern that the incorporation would curtail opportunities for disadvantaged students to enter university in future and regretted the discontinuation of the Vista programmes.

The following comments were received from participants:

I experienced the interview as meaningful . . . in that it provided an opportunity to think deeply about issues related to learning/teaching that are not often expressed in the dominant discourse in this area, particularly as Vista was and is perceived in strong negative ways as devoid of academic value in mainstream academic circles. The interview enabled me to analyse and synthesise my experience of teaching/ learning, to find suitable words to conceptualise, voice and express this knowledge we had created . . . This . . . gave rise to strong positive feelings of having my uniqueness, academic sense of belonging and community, identity, experience, and knowledge meaningfully acknowledged and validated.

Lao-zi said in the Dao De Jing: "We use bricks to build a house, but it is the space within, which makes it livable".

\section{CONCLUSION}

This research study reveals something of the experiences of a group that had found itself marginalised within established institutions of higher learning. However, it also highlights the plight of those segments of society that remain marginal to higher education. The themes elicited through the research reflect a process where university knowledge, in the sense of a pure, objective reading of the world, was challenged through an engagement with marginal, local contexts. They show how participants had to find ways to live purposefully amongst a 'mayhem' (Barnett 2000,409 ) of competing knowledges and learn to embrace an epistemology that is 'open, bold, engaging, accessible and conscious of its own insecurity' (2000, 409). Such an engagement with knowledge may be more liberating and appropriate to the current age of globalisation, and the current demands of higher education in South Africa, than more static conceptualisations of university knowledge. It may turn universities away from being endorsing machines of existing 'truths' to places where different frames of understanding can meet and new ones evolve. 


\section{NOTES}

1 I would like to thank my colleague Willem Louw for introducing me to this narrative form.

2 Bakker, T. M. 2005. Catching a feather: perceptions of indigenisation on Mamelodi Campus. Paper delivered at the International Society for Theoretical Psychology XIth Biannual Conference 2005, 20-24 June, Cape Town.

3 Available from the author on request.

\section{REFERENCES}

Abley, M. 2003. Spoken here: travels among threatened languages. London: William Heinemann.

Bakker, T. M. June 2005. Catching a feather: perceptions of indigenisation of psychology on Mamelodi Campus. Paper presented at the International Society for Theoretical Psychology XIth Biannual Conference 2005, Cape Town, South Africa, 20-24 June.

Bakker, T. M., L. M. Blokland, J. B. Fouché, L. Korf, M. S. May, A. Pauw, M. Petersen, R. Ratnam, R. Vermaak and G. A. Viljoen. 2000. Perceptions of psychology students from an historically black South African university of circumstances impacting on their lives. Journal of Psychology in Africa 10 (1): 26-47.

Barnett, R. 2000. University knowledge in an age of supercomplexity. Higher Education 40: 409-422.

Beverley, J. 2000. Testimonio, subalternity, and narrative authority. In Handbook of qualitative research (2nd edition), eds. N. K. Denzin and Y. S. Lincoln, 555-565. London: Sage.

- 2004. Testimonio: On the politics of truth. Minneapolis: University of Minnesota Press.

Bhabha, H. K. 1990. The other question: Difference, discrimination, and the discourse of colonialism. In Out there: Marginalization and contemporary cultures, eds. R. Ferguson, M. Gever, T. T. Minh-ha and C. West, 71-87. Cambridge: MIT Press.

Bouchenaki, M. 2003. The interdependency of the tangible and intangible cultural heritage. Keynote address. Proceedings of the International Scientific Symposium of the international Council for Monuments and Sites (ICOMOS). Victoria Falls, Zimbabwe, 27-31 October 2003. Available at: http://www.international.icomos.org/victoriafalls2003/papers.

Brulin, G. 2001. The third task of universities or how to get universities to serve their communities! In Handbook of Action Research: Participative Inquiry and Practice, eds. P. Reason and H. Bradbury, 440-446. London: Sage.

Brydon-Miller, M. 1997. Participatory action research: psychology and social change. Journal of Social Issues 53 (4): 657-666.

CHE. 2004. Council of Higher Education report on the first ten years of democracy. Available at: http://www.che.ac.za/documents/d000081/SA_HE_10years_Nov2004_Chapter7.pdf. Accessed on 16 February 2005.

Comaroff, J. and J. Comaroff. 1991. Of revelation and revolution: Christianity, colonialism and consciousness in South Africa (Vol. 1). Chicago: University of Chicago Press.

Creswell, J. W. 1998. Qualitative inquiry and research design. London: Sage.

Denzin, N. K. and Y. S. Lincoln, eds. 2000. Handbook of qualitative research (2nd edition). London: Sage.

Fanon, F. 1967. Black skin, white masks. New York: Grove Press.

Foucault, M. 1977. Discipline and punish: The birth of the prison. London: Penguin.

- 1980. Power/knowledge: Selected interviews and other writings, 1972-1977. Brighton, Sussex: Harvester Press.

Geertz, C. 1993. Local knowledge. London: Fontana. 
Gergen, K. J. 1999. An invitation to social constructionism. Thousand Oaks, CA: Sage.

Gergen, K. J. and M. M. Gergen. 1991. Toward reflexive methodologies. In Research and reflexivity, ed. F. Steier, 76-95. London: Sage.

Greenwood, D. J. and M. Levin. 2000. Reconstructing the relationship between universities and society through action research. In Handbook of qualitative research (2nd edition), eds. N. K. Denzin and Y. S. Lincoln, 85-105. London: Sage.

Heelas, P. and A. Lock, eds. 1981. Indigenous psychologies: the anthropology of the self. New York: Academic Press San Diego.

Humphreys, J. and J. Conlon. 2003. Higher education and local communities. South African Journal of Higher Education 17 (3): 66-73.

Kim, U. and J. W. Berry, eds. 1993. Indigenous psychologies: research and experience in cultural context. Newbury Park, Calif.: Sage.

Kraak, A. 2000. Changing modes: New knowledge production and its implications for higher education in South Africa. Pretoria: HSRC.

Kvale, S., ed. 1992. Psychology and postmodernism. London: Sage.

May, M. S., T. M. Bakker, H. T. Matla and N. Molefe. 1999. PSY 5005 module workbook: African perspectives in psychology. Vista University, Department of Psychology.

Ministry of Education. 1997. National plan for higher education. Pretoria: Ministry of Education, July 1997.

- 2002. Higher Education Act (No. 101 of 1997) as amended by Act 63 of 2002. Available at: http://education.pwv.gov.za.

- 2003. Higher education restructuring and transformation: Guidelines for mergers and incorporations. Pretoria: Ministry of Education, April 2003.

Mudimbe, V. Y. 1994. The idea of Africa. Bloomington: Indiana University Press.

Neuman, W. L. 2000. Social research methods: Qualitative and quantitative approaches. Needham Heights, MA: Allyn and Bacon.

Odora Hoppers, C. A., ed. 2002. Indigenous knowledge and the integration of knowledge systems: towards a philosophy of articulation. Cape Town: New Africa Books.

Randall, M. 1985. Testimonios: A guide to oral history. Toronto: Participatory Research Group.

Reason, P. and H. Bradbury. 2001. Inquiry and participation in search of a world worthy of human aspiration. In Handbook of action research: Participative inquiry and practice, eds. $\mathrm{P}$. Reason and H. Bradbury, 1-14. London: Sage.

Rorty, R. 1985. Solidarity or objectivity? In Post-analytic philosophy, eds. J. Rachman and C. West, 3-19. New York: Columbia University Press.

Seepe, S. 2003. Message from the Acting Vice Chancellor at the 21st Institutional Celebration of Vista University. In 21st Institutional Celebrations: Reflections on 21 years of service to disadvantaged communities, ed. T. Maimane, 7-9. Pretoria: Vista University.

South African Qualifications Authority. 2000. The National Qualifications Framework and Curriculum Development. Pretoria: South African Qualifications Authority, May 2000.

Steier, F., ed. 1991. Research and reflexivity. London: Sage Publications.

Toulmin, S. 1990. Cosmopolis: the hidden agenda of modernity. New York: Free Press.

Weingarten, K. 2001. Making sense of illness narratives: braiding theory, practice and the embodied life. In Working with the stories of women's lives, ed. C. White, 111-125. Adelaide: Dulwich Centre Publications.

White, M. 1990. Narrative means to therapeutic ends. New York: Norton. 